Obets. Revista de Ciencias Sociales. Vol. 6, n. ${ }^{\circ}$ 2, 2011; pp. 269-291

\title{
REDES ALTERNATIVAS DE COMUNICACIÓN, FRAMING Y LA CONSTRUCCIÓN DEL PODER POLÍTICO
}

\author{
ALTERNATIVE COMMUNICATION NETWORKS, FRAMING \\ AND CONSTRUCTION OF POLITICAL POWER
}

\author{
Mayra Martínez Avidad \\ Universidad Complutense de Madrid \\ mmavidad@hotmail.com
}

Recibido: 22/09/2011

Aceptado: 28/11/2011

\begin{abstract}
Resumen
El objetivo del presente artículo es analizar el papel de las redes alternativas de comunicación en la construcción del poder político a través del proceso de framing o enmarcado. En los últimos años, la capacidad del público para producir (nuestros) propios mensajes que potencialmente desafíen los encuadres fijados por la elite política se ha expandido enormemente con la llegada de Internet y las comunicaciones móviles. En este sentido, las redes virtuales son importantes porque pueden aumentar la capacidad de las masas para comunicarse entre sí transformando los marcos de referencia individuales en marcos interpretativos de carácter colectivo.
\end{abstract}

Palabras clave: encuadre; poder; redes alternativas de comunicación; autocomunicación de masas; comunicación política, modelo de activación en cascada.

\begin{abstract}
The aim of this paper is to analyze the role of alternative communication networks in the construction of political power through the process of framing. In recent years, the ability of the public to produce (our) own messages that potentially challenge those frames established by political elites has been importantly expanded by the advent of Internet and mobile communications. In this sense, virtual networks are important because they can influence the capacity of masses to communicate with each other transforming individual frames of reference into collective interpretative frames.
\end{abstract}


Keywords: framing; power; alternative communication networks; mass selfcommunication; political communication; cascading network activation.

\section{INTRODUCCIÓN}

El objetivo general de este trabajo se basa en desarrollar una teoría sobre el papel de Internet y las comunicaciones móviles en la construcción del poder político a través de los procesos de enmarcado o framing. Dado que el poder se basa principalmente en la capacidad para construir significados (discursos en términos de Foucault) y puesto que los significados sólo viven en las mentes humanas, el poder es análogo a la capacidad para modelar las mentes de las personas en torno a unos marcos específicos (Damasio 2003; Lakoff, 2008). Para entender el proceso de construcción de poder es preciso, por tanto, comprender los mecanismos de construcción de significados utilizados por los diferentes actores sociales, mecanismos que se crean y activan a través del proceso de enmarcado de los mensajes generados en el ámbito de la comunicación (Castells, 2009). Puesto que en cada sociedad conviven actores sociales con intereses divergentes y a veces contrapuestos, éstos luchan por definir unos marcos conforme a sus propios intereses. Según Castells, las elites de poder combaten porque sus mensajes ganen representatividad y vigencia en los medios de comunicación, el espacio donde se libra la batalla por los discursos y por el poder. Uno de los modelos analíticos más influyentes acerca de este proceso es el propuesto por Robert Etmant (2004). Conocido como activación en casca$d a$, el modelo trata de explicar el proceso multinivel de enmarcado en los medios en asuntos de política exterior en Estados Unidos. Dicho proceso comienza con la negociación entre los actores políticos y grupos de interés clave sobre los mensajes en torno a un hecho o política concreta. El proceso de establecimiento de agenda y framing es filtrado por los medios, quienes, siguiendo una jerarquía de influencia, proporcionan al público los marcos a partir de los mensajes recibidos de las elites políticas. Pero el público también es capaz de influir en los medios reaccionando a los marcos propuestos. Su poder para establecer un contramarco lo suficientemente potente para desafiar los inducidos por la elite depende, entre otras variables, de la cantidad de mensajes que sea capaz de generar y comunicar. Esta capacidad se ha visto multiplicada en la última década por las redes alternativas de comunicación que proporcionan, por primera vez en la historia, un espacio libre para la producción de mensajes y la conexión entre personas. En este sentido, las nuevas redes de comunicación son la fuente del nuevo poder adquirido por las masas para la construcción de significados, siendo también el origen, por tanto, de la descomposición de las estructuras jerárquicas de poder con la elite política y financiera a 
la cabeza. El presente estudio pretende servir, de hecho, como hipótesis alternativa acerca del flujo de poder en la construcción de marcos y significados desde el nacimiento del fenómeno definido por Castells (2009) como autocomunicación de masas. Para ello, utilizando como referencia el mencionado modelo en cascada de Entman, se estudiará el que podría ser el primer triunfo popular en España sobre el marco político oficial llevado a cabo a través de las tecnologías de la información y comunicaciones y con efectos inmediatos en el poder político: los atentados del 11-M en Madrid. La metodología elegida ha sido un análisis de contenido de los encuadramientos en torno a la autoría en los principales medios de comunicación españoles y una recopilación de los marcos en redes sociales y sistemas de mensajería instantánea SMS durante los días 11, 12 y 13 de marzo de 2004. Dicho análisis tratará de demostrar cómo los contramarcos establecidos por el público gracias a las redes alternativas de comunicación, influyeron decisivamente en los mensajes difundidos por la prensa y que a su vez, retroalimentaron a las elites opositoras hasta provocar el vuelco electoral el 14 de marzo.

\section{MARCO TEÓRICO}

\subsection{Conceptos de poder político}

El argumento de que las redes alternativas de comunicación ostentan un papel crucial en la construcción del poder político se inscribe dentro del marco teórico que señala el carácter relacional del concepto de poder. Desde esta perspectiva, poder es la red de alianzas presentes en un terreno cambiante de discursos y prácticas sociales que evolucionan conforme a unos intereses. Esta es precisamente la interpretación foucaultiana de poder, un proceso en constante movimiento, multidireccional y de comportamiento sistémico. Según Foucault (1970) cada grupo social alberga unas posiciones en continuo conflicto con el resto de actores que luchan por ver representados sus intereses en las instituciones sociales. Aquellos grupos con más representación en dichas instituciones tendrán más oportunidades para conseguir cristalizar en la sociedad aquellas normas sociales, leyes, ideas -discursos en términos de Foucault- favorables a sus intereses, aumentando así su dominio. Pero dado que los discursos son, en última instancia, una forma de pensar y concebir el mundo, el poder puede resumirse en la lucha dinámica e inestable por la construcción de sentido. Este es también el concepto de poder en Gramsci (1975), para quien la dominación no es una consecuencia del poder coercitivo (ejercido a través de la violencia, monopolio exclusivo de los Estados) sino que es fundamentalmente ideológica y consiste en la capacidad de modelar las imágenes, las ideas y los proyectos de las personas sobre el material cultural e ideológico de 
nuestro entorno social. No obstante, aunque la mayoría de las instituciones de dominación ensalzan unos discursos que benefician a determinados grupos y que perjudican a otros, el hecho de que esos discursos puedan ser renegociados, es decir, que sean construidos socialmente, significa que son dinámicos y sujetos a cambios. Para que estos cambios se produzcan las personas deben aprovechar los puntos de resistencia o espacios de oportunidad que se abren en el flujo de poder para romper alianzas, reagrupar relaciones y reposicionar estrategias. Este enfoque teórico se basa en las teorías sociológicas que durante las últimas décadas del siglo XX han desafiado la clásica dialéctica entre estructura y agencia ${ }^{1}$ (structure vs agency) entre ellas, la teoría de la estructuración social de Anthony Giddens (1984) y la teoría de la producción de la sociedad de Alain Touraine (1970). El estudio de Touraine de los movimientos sociales en la era post-industrial, demuestra de hecho el poder de la acción humana para alterar los discursos dominantes y transformar la forma de pensar de los miembros de la sociedad hasta el punto de modificar la práctica cotidiana y la realidad política.

\subsection{Funciones de representación mediática y poder político}

¿Pero dónde y cómo se libra esa batalla por la construcción de sentido? Castells (2009) propone que dicha batalla se libra en los medios de comunicación. "De hecho, aquellos mensajes, organizaciones y líderes que no tienen presencia mediática no existen para el público" (Castells, 2009: 261). Ello no significa, según Castells, que los medios ostenten el poder. "No son tampoco, el Cuarto Poder, sino algo mucho más importante: el espacio donde se crea poder" (Castells, 2009: 262). Los mecanismos a través de los cuales se crea ese poder se concretan en los dos procesos clave durante la emisión y recepción de los mensajes entre medios y personas: (1) el establecimiento de la agenda (agenda setting) y el (2) enmarcado (framing); es decir: (1) atrayendo la atención pública sobre un tema (politizándolo) y (2) enmarcando el debate sobre ese tema de modo que tenga efectos indirectos sobre la opinión pública (Castells, 2009). Ambos procesos pueden llamar la atención del Gobierno y otras elites clave y presionarles a reposicionarse en torno a este nuevo marco, lo que puede provocar cambios en la sociedad, cambios por lo tanto en la relaciones de poder. El establecimiento de la agenda es una de las teorías con más tradición en el estudio de los efectos de los medios. Se trata de la primera función de representación mediática y se refiere al orden de relevancia con que los medios

\footnotetext{
${ }^{1}$ Agencia (traducción del vocablo inglés agency) se refiere a la capacidad de los individuos para actuar de forma independiente y tomar libremente sus propias decisiones.
} 
transmiten una noticia. Según dicha teoría, los medios otorgan relevancia a unos determinados temas y ocultan otros, y al hacerlo, influyen en el público señalándole a qué asuntos deben prestar atención (McCombs y Shaw, 1972). Pero mientras el establecimiento de la agenda influye en los temas que la gente conoce y sobre los que la gente piensa, el proceso de encuadramiento influye en cómo se piensa sobre los temas ya establecidos por la agenda de los medios. Ello se consigue dando una visión particular sobre el asunto concreto. En este sentido, "el proceso de framing o enmarcado consiste en: seleccionar y subrayar unas determinadas facetas de los hechos acaecidos y establecer relaciones entre éstos, de manera que promuevan una interpretación particular, evaluación, o solución" (Entman, 2004, 5). La importancia de estos enfoques particulares reside en que, al influir en la manera de interpretar los acontecimientos, condicionan a su vez las respuestas políticas que se toman hacia ellos. "Por ejemplo, en el caso de los ataques terroristas del 11 de septiembre, el entonces Presidente Bush, definiendo el acto en términos de un "acto de guerra" en la mañana siguiente a los atentados e invocando la palabra "malvado" y "guerra" varias veces en su discurso sobre el Estado de la Nación en 2002, lograba enmarcar los acontecimientos de forma que conseguía una apabullante aprobación pública sobre sus planes de intervención en Irak" (Entman, 2004,1). Tanto el establecimiento de la agenda, como el framing, conforman los procesos que inducen a una determinada forma de interpretar la realidad y que contribuyen, por extensión, a la construcción de la realidad social y política.

\subsection{El framing en la construcción de la realidad social}

El auge de las teorías de constructivismo social durante los años 80 provocó que la investigación de los efectos de los medios, y en concreto las teorías de framing en el área de la comunicación política, tomaran este nuevo enfoque teórico (Scheufele, 1999). Dicho enfoque reconoce unos efectos poderosos de los medios al presuponer que impactan fuertemente en la construcción del acontecer proporcionando activamente los marcos de referencia que la audiencia usa para interpretar y discutir sobre los asuntos públicos. No obstante, estos efectos se ven atenuados por aquellos elementos que influyen en cómo las personas procesan e interpretan la información, como la propia experiencia personal, las interacciones con otras personas y la selección que se haga dicha información (Klapper, 1960). En este sentido, según señala Scheufele (1999: 106), "las investigaciones sobre framing como un modelo interactivo de construcción de la realidad han combinado las aproximaciones individuales de cómo los individuos procesan significados (primer nivel) con los procesos socioculturales que determinan los discursos que asumen los medios de comunicación (segundo 
nivel)". Las primeras teorías de los medios de comunicación que profundizaron en este último aspecto fueron las teorías de corriente marxista que durante los años 60 y 70 analizaron los mecanismos mediante los cuales las clases dirigentes conseguían fijar y mantener sus definiciones de la realidad favorables. Según la teoría de la Hegemonía (Gramsci, 1975) y otras Teorías Críticas de los Medios (Marcuse, 1964; Althusser, 1969) las clases dirigentes se servirían de su acceso privilegiado a los medios de comunicación para difundir valores que legitimaran la existente distribución de poder. Por su parte, los medios, reproduciendo un repertorio común de ideas y símbolos contribuirían a su vez a diseminar ciertos valores que refuerzan el control político y económico. Esta visión determinista sobre el papel de los medios de comunicación en la construcción del poder político fue, sin embargo, modificándose en etapas posteriores. Aunque los más recientes modelos que relacionan el estudio del encuadre con la construcción de poder siguen situando a los medios en el centro del proceso de construcción del poder ideológico, (puesto que es en la esfera mediática donde se definen los marcos sobre los que se interpreta el mundo) éstos no se consideran una mera función de control político institucionalizado, sino un actor social más, con intereses y motivaciones propias, a veces en conflicto directo con los de la elite política. Desde esta perspectiva, aunque las elites -debido a su posición de dominancia inicial- cuentan con más posibilidades para fijar sus marcos favorables, no poseen el monopolio completo sobre el encuadre o el discurso. En algunos casos, los marcos oficiales pueden ser desafiados por contramarcos promovidos por otros actores sociales. Incluso, dependiendo de las circunstancias concretas, los medios pueden cooperar en la difusión de estas versiones contrarias.

\subsection{Framing y hegemonía ideológica}

Las primeras investigaciones en el campo de la sociología de la comunicación que relacionaron el proceso de framing con la hegemonía ideológica analizaron en qué casos los medios apoyan las versiones oficiales sobre diferentes asuntos políticos. Hallin (1986 y 1994) documentó, por ejemplo, que la fuerte unidad entre la elite política americana sobre la necesidad de intervención en la guerra de Vietnam provocó que los medios asumieran una función legitimadora de la ideología política dominante. Sólo cuando empezó a ser visible el clima de disidencia, los periodistas americanos se posicionaron de forma neutral frente a las diferentes posiciones y puntos de vista. Aunque "la multiplicidad de conceptos sobre framing y la tendencia a reducirlo a un mero efecto de los medios provocó, entre otros factores, que durante algunos años se dejaran de lado los enfoques que conectaban el proceso de framing con la teoría de la hegemonía" (Carrafee y Roefs, 2004: 214), estamos presenciando renovado interés por rela- 
cionar framing y poder en las áreas de comunicación política (Livingston y Bennet, 2003; Entman, 2004) y la sociología de la comunicación (Castells, 2009). Los nuevos modelos analizan cómo las asimetrías de poder influyen en el proceso de encuadramiento y prestan especial atención a la capacidad de la ciudadanía para impactar en el proceso de framing mediático y, por tanto, desafiar las estructuras de poder político. Estos nuevos modelos proponen que la opinión pública es capaz de desestabilizar el poder político a través de la producción de frames colectivos. De hecho, "gran parte del éxito de muchos movimientos sociales que emergen de grupos marginados se debe al triunfo de sus encuadres en los medios de comunicación, lo que les sirve para subrayar sus preocupaciones, movilizar apoyos y validar su existencia como actores sociales" (Carragee y Roefs 2004: 225). Gamson (1992)² identificó tres dimensiones de encuadres de acción colectiva: un componente de injusticia (la identificación de un daño producido por la acción humana), un componente de autonomía (la creencia de que es posible el cambio mediante la acción colectiva), y un componente de identidad (la identificación de un adversario específico). Castells (2009), basándose en los estudios de Damasio (2003) ha identificado, asimismo, que la pérdida del miedo es un componente esencial que contribuye a la movilización colectiva.

\section{MODELOS ACTUALES DE ENMARCADO Y CONSTRUCCIÓN DE SENTIDO EN LA ESFERA MEDIÁTICA}

Entre los modelos que han tratado de explicar los mecanismos y oportunidades para desafiar la versión oficial a través de la construcción de marcos alternativos destacan el influyente modelo de análisis interpretativos de Entman (2005) y el reciente modelo de sociedad red de Castells (2009). Aunque el primero restringe su aplicación al proceso de enmarcado en política exterior en Estados Unidos y el segundo es un análisis global del papel de las redes de comunicación en la construcción del poder político (en el que ya se otorga un papel relevante a las redes alternativas de comunicación), ambos reconocen: (1) que lo que en última instancia determina el poder político son los marcos que logran imponerse en la esfera mediática; (2) que cada actor dominante lucha por imponer un marco que responde a sus intereses y valores; y (3) que el triunfo sobre el enmarcado dependerá de un conjunto de variables que vienen determinadas por las posiciones, estrategias y relaciones entre los diferentes actores.

\footnotetext{
${ }^{2}$ Citado en Carragee y Roefs (2004: 226)
} 


\subsection{Modelo en Cascada de Entman}

El modelo de "activación en cascada" de Entman (2005) aborda los procesos de agenda setting, framing y primming, en un único sistema compuesto por varios niveles de actores dispuestos en cierto orden de jerarquía. Los niveles que componen este sistema en cascada son, según el autor, (1) El Gobierno, (2) Otras Elites, (3) Medios, (4) Encuadres y, (5) Público (Figura 1). Entman muestra que el punto inicial de transmisión para difundir la activación de los encuadres sigue siendo los altos funcionarios de la administración pública. Esto es así porque disponen de información privilegiada sobre asuntos de política internacional y sus decisiones tienen más peso en dicho asuntos (Castells, 2009). Este marco oficial es filtrado por el resto de elites hasta los medios, quienes eligen los marcos de referencia iniciales que llegan al público. Sin embargo, es importante señalar que estos marcos iniciales retroalimentan al nivel superior (al resto de elites) y que cada nivel puede reaccionar aceptando el frame oficial o lanzando una contra ofensiva de encuadramiento. Según Entman, los factores que determinan quién gana la batalla del encuadre tienen que ver con la posición inicial de cada actor social, su estrategia a la hora de definir el frame o contraframes, sus motivaciones e intereses y la naturaleza misma del encuadre. En este último sentido establece que, "cuanto más congruentemente es un frame con los esquemas dominantes de la cultura política, mayor será el éxito con el que contará" (Entman, 2004: 14). Ello se debe a que los esquemas habituales se instalan en la mente de los individuos casi sin ningún coste cognitivo. Por el contrario, si los acontecimientos son ambiguos y existe discrepancia entre las elites, el Gobierno tendrá más dificultades para fijar su marco favorable. También, en ocasiones, la elite gobernante tendrá que hacer frente a las ofensivas de enmarcado del resto de actores sociales, que movidos por sus propios intereses, podrán intentar hacer triunfar una interpretación diferente de la oficial. Las motivaciones que alberga la elite oponente para oponerse al encuadre definido por el Gobierno son claras: avanzar en la carrera política. Pero no son los únicos, también para los periodistas puede resultar atractivo desafiar la visión oficial. Los intereses de los periodistas son diversos y van desde los meramente profesionales, a las motivaciones empresariales que suelen imponer los dueños de los medios para los que trabajan (Schudson, 2003), pasando por los intereses fundamentalmente políticos ${ }^{3}$.

3 Según Castells (2009: 263), los dueños de los medios también albergan intereses políticos, ya que se encuentran directamente implicados en la dinámica del Estado, que es una parte fundamental de su entorno empresarial. 
FIGURA N. ${ }^{\circ} 1$

Activación en cascada del encuadre

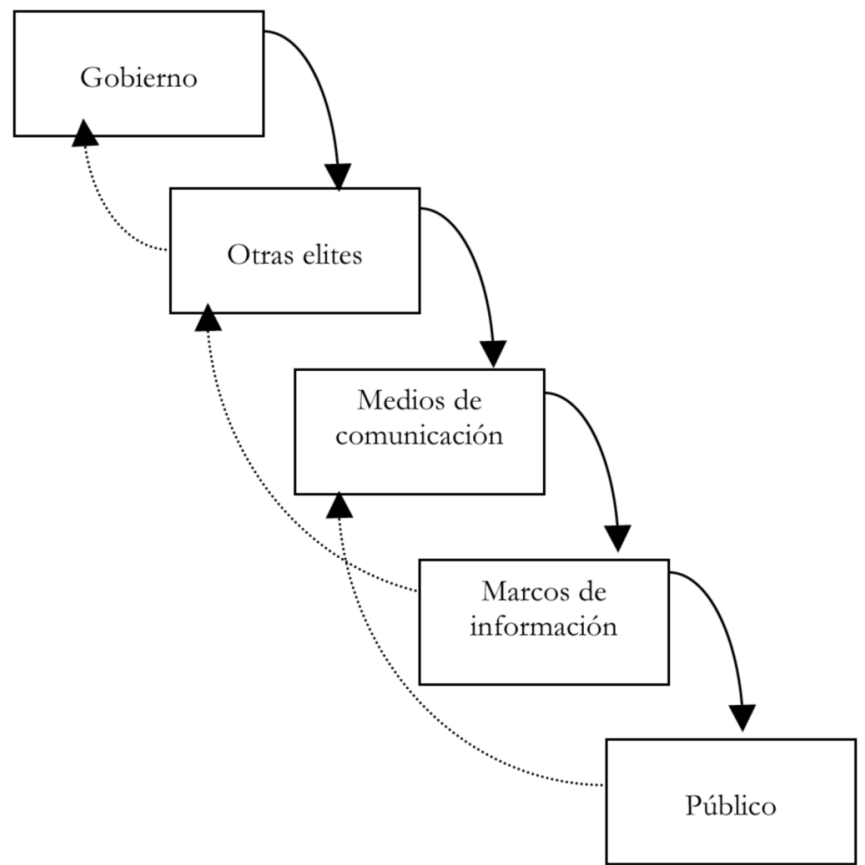

Fuente: Adaptado de Entman (2004: 10, figura 1.2)

\subsection{Modelo de sociedad en red de Castells}

Más recientemente Castells (2009) ha proporcionado un exhaustivo análisis de los intereses, motivaciones, relaciones e influencias recíprocas existentes entre las distintas redes dominantes y que determinan la construcción de los discursos en la esfera mediática. Según su descripción "el poder es multidimensional y se construye en redes programadas en cada ámbito de actividad humana según los intereses y valores de los actores empoderados" (Castells, 2009: 547). Aunque la red política trata de construir unos significados favorables con los que ganar influencia en la opinión pública haciendo uso de su maquinaria de comunicación y de marketing, Castells señala que ello no puede hacerse sin tener en cuenta el propio interés comercial de los medios. Así, por ejemplo, si un candidato pretende que su mensaje sea recogido y difundido por un noticiero de un canal de televisión aquel debe someterse a las reglas de lo noticiable, es decir, ser novedoso, inesperado, llamar la atención (de ahí el gran auge de la política del escán- 
dalo) y adecuarse a las características del formato del medio en cuestión: en el caso de la TV, el mensaje deberá ser corto, puesto que las apariciones televisivas nunca exceden de unos pocos segundos ${ }^{4}$. Acomodándose a la lógica comercial de los medios, el poder financiero también consigue construir significados acorde a sus intereses. Financiando parte de la actividad de los medios a través de la publicidad, las grandes corporaciones logran ejercer un gran impacto en la definición de la cultura y los estilos de vida conforme a las estrategias empresariales. Pero sería ingenuo pensar que los medios sólo sirven como plataforma propagandística de los diferentes poderes. Las corporaciones mediáticas necesitan, para su subsistencia, ser a su vez creíbles y aportar un valor. Es así cómo la red ciudadana ejerce cierta influencia sobre los marcos elegidos por los medios, marcos que deberán cumplir las expectativas de una información atrayente, independiente y de calidad. Por otro lado, si entre la red ciudadana surge un movimiento de extensiones llamativas, su mensaje será recogido y difundido por los medios de comunicación animando la reacción de los demás actores y alterando las posiciones iniciales. De hecho, los encuadres y mensajes que difunden los medios provenientes de movilizaciones ciudadanas impactan en muchas de las decisiones políticas, así como en la percepción y toma de decisiones de banqueros y hombres de negocios en todo el mundo.

\section{REDES ALTERNATIVAS DE COMUNICACIÓN Y PODER POLÍTICO}

\subsection{Internet y las redes móviles en la construcción de frames colectivos}

Pero la capacidad de la opinión pública para fijar la agenda y enmarcar los discursos en la esfera mediática se ha multiplicado exponencialmente con la llegada de la Red y las comunicaciones móviles y su penetración en todos los ámbitos de la sociedad. Castells (2009) señala que, gracias a Internet, la red ciudadana cuenta hoy con la capacidad de participar en la producción cultural, de desarrollar redes independientes de comunicación horizontal y de construir significados alternativos. Por primera vez en la historia, los mensajes son producidos por y para las masas, pudiendo llegar a cambiar el rumbo de los acontecimientos si consiguen movilizar a un número suficiente de personas. El potencial de estas redes alternativas de comunicación se basa en la capacidad de las masas para comunicarse entre sí (auto-comunicación de masas ${ }^{5}$ ), el des-

\footnotetext{
${ }^{4}$ Según documentó Daniel Hallin en 1992, las frases efectistas (soundbites) de los candidatos se redujeron de 40 segundos en 1968, a 10 segundos en los años 80 .

${ }^{5}$ Por 'autocomunicación de masas' Castells (2009) entiende la capacidad de cada persona de emitir sus mensajes, seleccionar los mensajes que desea recibir, organizar sus propias redes e interactuar con otras personas que a su vez deciden autónomamente su participación en esas redes virtuales.
} 
lizamiento de los marcos de referencia individuales hacia marcos interpretativos colectivos compartidos y su potencial de impacto en la esfera mediática. El análisis de Castells revela que el origen de este tipo de comunicaciones está relacionado con el surgimiento de nuevos mercados ligados al desarrollo de la industria de las TIC. Las empresas de Internet (Google, Facebook, Twitter) ofrecen a los ciudadanos libre acceso al ciberespacio a cambio de renunciar a su privacidad y de convertirse en objetos publicitarios ${ }^{6}$ (Castells, 2009). Pero en contrapartida, las empresas acuerdan respetar un principio básico y fundamental de prestación de servicio: el de no interferencia. La libertad con la que las masas pueden interactuar en Internet les permite conectar entre sí, compartir mensajes e información de manera instantánea, formar explicaciones alternativas sobre los acontecimientos y organizarse para movilizarse fuera del espacio virtual, es decir en las propias calles.

Algunas de las características distintivas de estas redes alternativas de comunicación tienen mucho que ver con las identificadas en los medios alternativos, entre ellas su carácter auto-organizativo, sus posibilidades para la participación ciudadana, así como sus facultades contra-hegemónicas, aspecto este último analizado con relativa frecuencia en la literatura académica reciente (Atton, 2002, 2004; Couldry and Curran, 2003). No obstante, las redes alternativas de comunicación no se caracterizan por el carácter crítico de sus mensajes hacia las estructuras de dominación y poder, si no por ser en sí mismos medios de expresión de la ciudadanía, un espacio similar a la esfera pública imaginada por Habermas (1989), en la que los ciudadanos intercambian libremente opiniones, ideas y demás formas de expresión, y en donde última instancia se gesta el clima de opinión. Se trata de la vía mediante la cual la opinión pública puede competir en mejores condiciones (porque ahora dispone del espacio virtual para hacerlo) con la elite dominante en la construcción de significados. Y es precisamente este aspecto lo que convierte a estas redes en fuentes de contra-poder. Los nuevos marcos surgidos en el ciberespacio pueden impactar en la esfera mediática, influir en las estrategias de otros actores sociales, derivar en movilizaciones en el espacio físico o, como con mayor frecuencia se está investigando, iniciar movimientos sociales (Törn, 2007).

Ejemplos de estas redes construidas alrededor de Internet y la telefonía móvil serían, por tanto, redes sociales como Facebook y Twitter, blogs, servicios de mensajería móvil tipo SMS, plataformas para subir y compartir vídeos como Youtube, pero también medios alternativos abiertos a la participación ciudadana como Indymedia o Nodo50. Quedarían sin embargo excluidos otro tipo de medios también considerados alternativos por autores como Christian Fuchs

${ }^{6}$ Es lo que Castells (2009) denomina la 'mercantilización de la libertad' 
(2010) por sus contenidos críticos hacia la ideología dominante, pero que sin embargo se editan exclusivamente por profesionales ${ }^{7}$. Fuchs considera, por ejemplo, que los medios alternativos organizados por el propio público son incapaces de producir una contra-esfera a gran escala, con lo que se reduce significativamente su potencial de transformación política. Sin embargo, si consideramos la capacidad viral de transmisión de mensajes de sitios como Facebook o Youtube, nos damos cuenta de su potencial. Aunque una red social no es un medio de comunicación mainstream (aquella no cuenta con una estructura rígida y centralizada y sí permite la participación social en el proceso de producción mediática), ni tampoco estrictamente un medio de comunicación alternativo (aquella no se creó con el fin de proveer una plataforma para difundir puntos de vista radicales o alternativos), una red social, como el resto de plataformas de la Web 2.0 son algo más que meros "sistemas de comunicación humana" (Fuchs, 2011: 270). Éstas pueden considerarse medios de comunicación en tanto que permiten la creación, producción y diseminación de mensajes entre emisores y receptores.

\subsection{Críticas a la relación entre redes alternativas y poder político}

El interés por estudiar el impacto de las tecnologías de la información y las comunicaciones en el proceso político se ha intensificado enormemente en los últimos años. No obstante, lejos de existir un acuerdo unánime sobre su impacto, existe de hecho una línea de investigaciones que revelan un marcado escepticismo. Algunas de las críticas sobre la capacidad que puedan albergar estas redes de comunicación para desafiar la ideología dominante han venido de investigaciones sobre su impacto en asuntos de política internacional. Dichas investigaciones en la línea de los CNN effects (Livingston y Bennet, 2003), han concluido, que mientras la llegada de los medios globales en los años 80 y 90 permitió que el público fuera inmediatamente consciente de las decisiones políticas en materia de asuntos exteriores, acelerando y afectando en gran medida el proceso de toma de decisiones en torno a intervenciones bélicas y humanitarias, las tecnologías de la información no suponen un salto cualitativo en los mismos términos. Piers Robinson (2011) pone de ejemplo los movimientos en contra de la Guerra de Irak y Afganistán en el Reino Unido, que alimentados en los medios alternativos en Internet, no consiguieron cambios sustantivos en la política internacional del Gobierno de Blair. Sin embar-

${ }^{7}$ Fuchs (2011: 177) considera medios alternativos algunos medios internacionales de gran tirada editados por periodistas profesionales como New Internationalist, Le Monde Diplomatique, Z Magazine, Rethinking Marxism, Historical Materialism, Monthly Review o New Left Review. 
go, la falta de autonomía de la opinión pública para cohesionar un frame colectivo contrario puede ciertamente deberse a la ausencia de los factores citados por Gamson (1992) y el propio Castells. En la misma línea crítica Evgeny Morozov (2011) ha señalado por su parte, que líderes de regímenes autoritarios en diferentes regiones del mundo utilizan las herramientas tecnológicas de la comunicación para encontrar apoyo a sus propias interpretaciones y definiciones favorables, a veces con excelentes resultados ${ }^{8}$. En este sentido, Morozov acierta al afirmar lo ingenuo que resulta creer que la tecnología convierte a las personas en más proclives a apoyar valores democráticos. De hecho, de forma reciente se ha observado cómo los talibanes están también haciendo uso de Twitter para impulsar su propio movimiento9. En este sentido hay que puntualizar que la existencia de un nuevo y extenso terreno comunal virtual abre la puerta a la construcción individual de significados, pero en ningún caso define la naturaleza de los mismos. La fuente de poder estriba simple y llanamente en la capacidad de producir y conectar significados en el espacio virtual, de manera que puedan ganar peso e importancia en el espacio físico, consiguiendo calar en la esfera mediática y por ende contribuyendo a transformar la realidad social y política. De esta manera, el poder que una persona atesore al difundir una determinada idea en las redes alternativas de comunicación dependerá de con cuántas personas que piensan como ella logra conectar y aliarse en coalición o a cuántas logra convencer. En palabras de Castells (2009: 553):

La mente pública se construye mediante la interconexión de mentes individuales como la suya. Así que, si piensa de otra manera, las redes de comunicación funcionarán de otra manera, con la condición de que no sea usted solo, sino muchos, los que estemos dispuestos a construir las redes de nuestras vidas.

\section{ESTUDIO DE LAS REDES ALTERNATIVAS DE COMUNICACIÓN EN EL PROCESO DE ENMARCADO POLÍTICO}

\subsection{Hipótesis}

La rápida penetración de las redes de comunicación alternativas y su enorme influencia en la capacidad con que la ciudadanía puede desafiar los marcos

\footnotetext{
${ }^{8}$ Morozov menciona el caso de Tailandia donde se creó un sitio en Internet animando a los usuarios a enviar links sobre aquellas páginas o contenidos en la Red que pudieran ser ofensivos para el Rey -lo que le permitió bloquear 3.000 páginas de Internet en 24 horas-; o el caso de Arabia Saudí donde los internautas son llamados a buscar vídeos que hieran la sensibilidad saudí, con el fin de que un número elevado de quejas fuerce a Youtube a eliminar de la plataforma aquellos vídeos considerados ofensivos.

${ }^{9}$ Boone, Jon. Taliban join the Twitter revolution. Theguardian.co.uk (en línea). 12 de mayo de 2011. Disponible en Internet: http://www.guardian.co.uk/world/2011/may/12/taliban-jointwitter-revolution?CMP=twt_gu
} 
FIGURA N. ${ }^{\circ} 2$

Las redes alternativas de comunicación en la activación en cascada del encuadre

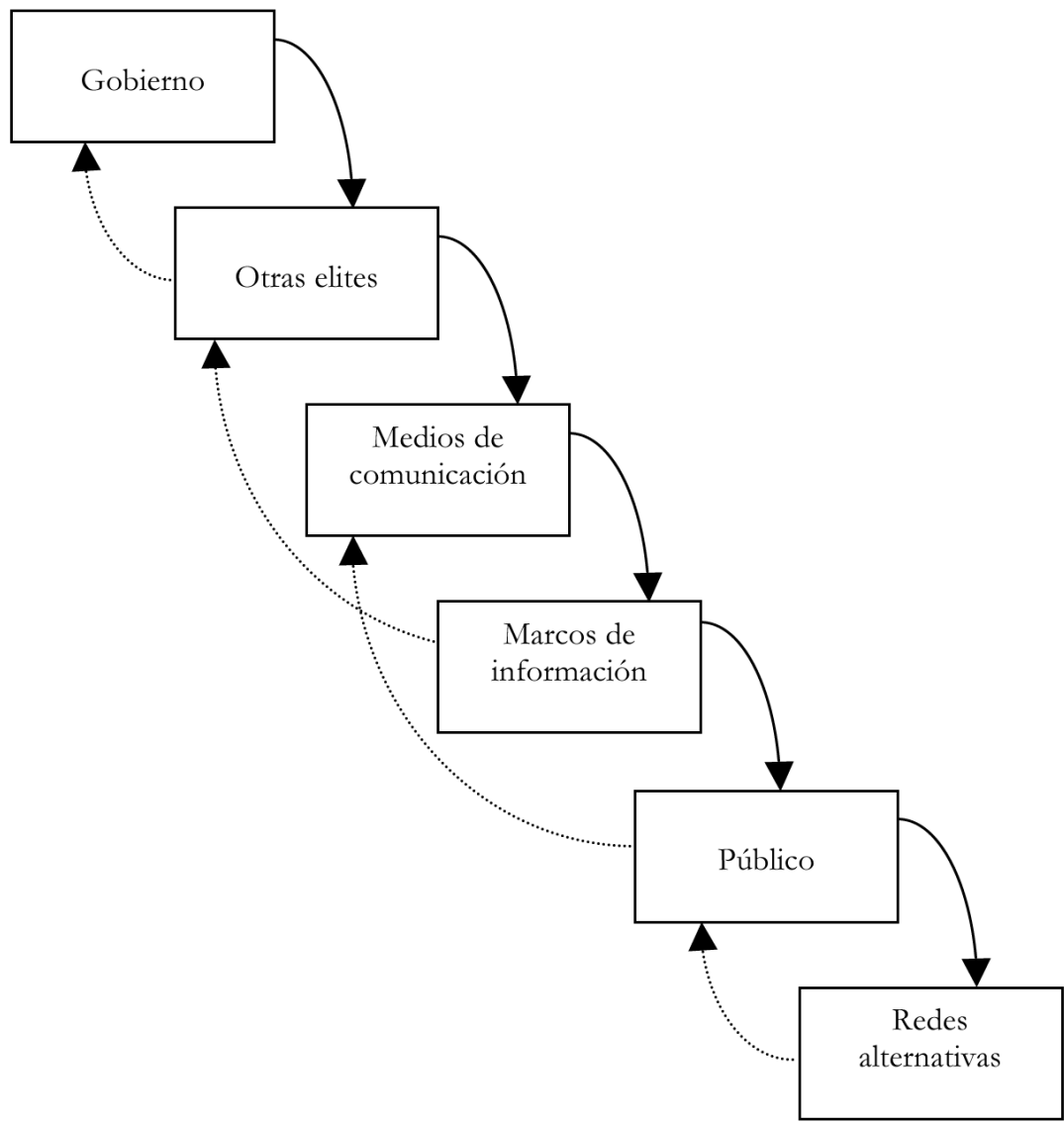

Fuente: Adaptado de Entman (2004: 10, figura 1.2)

establecidos por las elites dirigentes, obliga a realizar una revisión de los paradigmas del proceso de enmarcado en el ámbito de la comunicación política. Dichos paradigmas están percibiendo la influencia de las redes de comunicación y empiezan a considerarlos una parte fundamental en los mecanismos de construcción de la realidad social y política. En este sentido, la hipótesis que se maneja es un modelo revisado de enmarcado sobre asuntos de política exterior basado en el propuesto por Entman, en el que las redes alternativas de comunicación se conforman como un sexto nivel en la activación de redes en casca- 
da. Tras los marcos de información establecidos por los medios, el público tendría la oportunidad de fijar nuevos marcos en las redes alternativas de comunicación que pueden influir en los contramarcos que se filtran de nuevo a los medios. Este alcance que ofrecen las redes alternativas de comunicación viene dado en gran medida por la capacidad de conexión y difusión instantánea de mensajes, pero también, por la productividad que otorgan al público a la hora de organizarse y movilizarse en el espacio físico, donde los mensajes consiguen calar más eficazmente en los medios. Internet también conformaría el espacio donde el público accedería y procesaría los marcos fijados por los medios de comunicación extranjeros, así como los encuadres y mensajes difundidos por blogs, perfiles sociales de líderes de opinión en otros países y que, dependiendo de las circunstancias concretas, podrían contribuir a desafiar los definidos por los medios nacionales (Figura 2).

\subsection{Caso de estudio}

Para la validación de esta hipótesis analizamos el encuadramiento sobre la autoría de los atentados del 11 de marzo de 2004 en Madrid. Estos atentados consistieron en 10 explosiones provocadas por diez mochilas cargadas con alto explosivo en cuatro trenes de la red de Cercanías de Madrid que se saldaron con 191 muertos y 1.857 heridos $^{10}$. Los ataques fueron cometidos tres días antes de las elecciones generales celebradas el 14 de marzo en España. En ese momento gobernaba en el país el Partido Popular (PP) quien, junto a la mayoría de los partidos políticos, atribuyeron durante las primeras horas el atentado a la banda terrorista ETA ${ }^{11}$. No obstante, la pérdida de control del PP sobre el encuadre de ETA en los dos días siguientes influyó significativamente en las elecciones presidenciales provocando un cambio de Gobierno. La hipótesis que se baraja es que esta pérdida de control sobre el encuadre no respondió -como normalmente ocurre- a un disentimiento expreso de la elite oponente, sino que el verdadero contra-frame surgió en Internet (los marcos que difundieron los usuarios de las redes alternativas) y que éste logró triunfar a tiempo para transformar la realidad política (vuelco electoral) gracias a su influjo en las movilizaciones previas a las elecciones.

\footnotetext{
${ }^{10}$ Se trata del segundo atentado más letal por víctimas mortales y el primero en términos de heridos que Europa había sufrido hasta la fecha desde tiempos de paz.

${ }^{11}$ Cabe señalar que la autoría de ETA beneficiaba los resultados electorales del PP, quien había demostrado una política muy dura y eficaz contra la banda terrorista vasca, mientras que la autoría de AlQaeda podría suponer una pérdida de votos, al verse interpretada como un castigo a la participación española en la guerra de Irak, intervención desaprobada por la amplia mayoría de la opinión pública española.
} 


\subsection{Metodología}

Para establecer cómo transcurrió la lucha de encuadramientos y la influencia de las estrategias de cada una de las partes involucradas en el conflicto, se llevó a cabo un análisis de contenido de las informaciones aparecidas en la prensa española desde el día de los atentados al día anterior a las elecciones. Los tres diarios elegidos para el análisis fueron El País, El Mundo y La Razón. En cuanto a la muestra, se cuantificaron la totalidad de las informaciones dedicadas al atentado, sometiendo a análisis sólo aquellas que aludían directa o indirectamente a la cuestión de la autoría, se apuntara o no a un autor concreto. Las unidades de análisis fueron por tanto, todas las noticias y artículos de opinión publicados por los mencionados diarios durante un marco temporal que abarcó los días 11, 12 y 13 de marzo ${ }^{12}$. La selección de la muestra se hizo con la intención de poder abarcar la máxima amplitud temporal y el abanico ideológico presente en la prensa española ${ }^{13}$. En total se analizaron 129 noticias (11 noticias el 11-M, 77 noticias el 12-M y 41 el 13-M). Para las conclusiones finales, los resultados de este análisis se compararon con el análisis de contenido del encuadre en torno a la autoría en medios alternativos y redes sociales de Roíg y López (2005).

Las variables de análisis se organizan en dos grandes bloques:

1. Los encuadres de los distintos actores sociales a los que la prensa daba cobertura $^{14}$. Se codificaron los encuadres sobre la autoría del (1) Gobierno, (2) el resto de elites y (3) el público.

2. Los encuadres privilegiados por la prensa según el tipo de información suministrada. Para ello se hizo una clasificación de (1) los argumentos que favorecían el encuadre de ETA y (2) los argumentos que favorecían el encuadre de AlQaeda ${ }^{15}$.

12 Para el análisis del día de los atentados (11 de marzo) se eligieron los artículos publicados por La Razón en su edición especial de por la tarde. El análisis del día 12 abarca las ediciones de los tres diarios, La Razón, El Mundo y El País. Mientras que para el último día de análisis el estudio se centró en sólo los artículos publicados por el diario El País.

${ }^{13}$ Recuérdese que en España se da el fenómeno definido por Hallin y Manccini (2004) como 'paralelismo político', el cual indica un alto grado de politización de los medios de comunicación y una simetría política de cada medio y con un determinado partido político.

${ }^{14}$ Se cuantificaron cada una de las explicaciones de los diferentes actores sociales sobre la autoría de los atentados y se clasificaron en cuatro categorías diferentes: (1) atribuciones explícitas a ETA, (2) atribuciones explícitas a AlQaeda, (3) posibilidad de que ambos grupos hubieran trabajado juntos, (4) teoría de la manipulación informativa.

${ }^{15}$ Se consideraron argumentos que favorecían el encuadre de ETA, todas las referencias a (1) las pruebas policiales que apuntaban a la pista de ETA (los materiales usados en los atentados, por ejemplo); (2) la captura de una furgoneta con material explosivo en manos de ETA durante la campaña electoral; (3) la poca credibilidad que se otorgaba a la 


\subsection{Resultados}

\subsubsection{Día 11 de marzo}

- Se da plena cobertura a la tesis del Gobierno, quien atribuye la autoría a ETA de forma explícita en 4 ocasiones.

- El encuadramiento oficial disfrutó de casi absoluta preponderancia: de las voces opositoras a las que se dio cobertura, ninguna desafió el frame oficial con la única excepción del portavoz de la extinguida Batasuna, Arnaldo Otegui.

- La única mención al encuadre del público provino de un ciudadano que respaldó también la tesis de ETA.

- En cuanto al encuadre que reflejan las informaciones, se contabilizan 7 argumentos que favorecen la tesis de ETA, frente a 4 que favorecen la de AlQaeda.

\subsubsection{Día 12 de marzo}

- Se recogen 20 atribuciones explícitas del Gobierno a la banda separatista vasca, frente a un sólo argumento que baraja la posibilidad de que ETA y AlQaeda trabajaran juntas.

- La gran mayoría de actores sociales respalda esta versión oficial. Se cuantifican 28 atribuciones a ETA frente a 6 atribuciones a AlQaeda del resto de elite española en la prensa de ese día.

- Entre los encuadres de la opinión pública a los que se da cobertura, se contabilizan 3 referencias a ETA frente a 1 referencia a AlQaeda.

- Los editoriales y artículos de opinión apoyan decididamente el encuadre oficial (ninguno, al menos lo desafía).

- Si observamos los argumentos más privilegiados en las informaciones, se percibe una clara tendencia a favorecer la tesis del terrorismo vasco: 79 argumentos que respaldan la tesis de ETA, frente a 51 que favorecen la hipótesis del terrorismo islámico.

célula de AlQaeda que reivindicaba la responsabilidad (se había probado falsa su participación en el apagón de Washington en 2003); y (4) el problema del País Vasco. Por su parte, se consideraron argumentos que favorecían el encuadre de yihaidista todas las referencias a (1) pruebas policiales que señalaban a la participación de Al Qaeda; (2) la carta enviada por el grupo Brigades Abu Hafs Al Masri al periódico musulmán Al Qods Al Arabi con base en Londres; (3) la negación de la banda ETA sobre cualquier relación con los ataques; (4) referencias a la implicación española en la Guerra de Irak (un ataque de AlQaeda sería la consecuencia de la participación española); (5) una posible manipulación informativa del Gobierno; y (6) informaciones acerca de gobiernos extranjeros preocupados por la posibilidad de un ataque islámico. 


\subsubsection{Día 13 de marzo}

- La prensa sigue recogiendo el encuadre del Gobierno, quien continúa señalando a ETA como la hipótesis más verosímil. Se computan 4 referencias explícitas de la Administración a la banda terrorista vasca.

- Se da más cobertura a los encuadres de la opinión pública que en días anteriores. Dos ciudadanos se declaran contrarios al enfoque del Gobierno (se decantan por la hipótesis de AlQaeda), 1 hace referencia a ETA y 5 expresan su preocupación ante una posible ocultación de información por parte del Gobierno.

- Se da cobertura a la primera ofensiva de la elite oponente en la lucha por el control del encuadramiento entorno a la manipulación informativa. En 5 ocasiones personalidades públicas apuntan al encuadre de la manipulación y en seis ocasiones se apunta decididamente a AlQaeda. Todavía existen, sin embargo, 8 atribuciones a ETA de actores internacionales y personalidades públicas españolas.

- Se baraja por primera vez el debate en torno a la manipulación en los editoriales y artículos de opinión de este día.

- Importante incremento del número de referencias los argumentos que fomentaban el contra-frame. En total se contabilizaron 50 argumentos que apoyaban la tesis de ETA, frente a 23 que favorecían la tesis islamista.

Sin necesidad de someter a un análisis de contenido a las informaciones del 14 de marzo, una primera vista a las portadas de los distintos diarios nos ofrece una casi unánime atribución al terrorismo islámico ${ }^{16}$. Los datos indican, por tanto, que el vuelco del encuadre tuvo lugar del día 12 al día 13 de marzo y que el triunfo completo del mismo se produjo el mismo día de las elecciones.

\subsection{Análisis de medios alternativos y redes sociales de Roíg y López (2005)}

Esta evolución de los encuadres en la esfera mediática, dista mucho de la que se produjo en las redes alternativas en Internet donde, casi desde las primeras horas tras los ataques, se pone en duda la versión del Gobierno. Si atendemos a los datos recogidos por Roíg y López (2005: 206) sobre la atribución de la autoría en los cuatro medios telemáticos más consultados durante esos días ${ }^{17}$ encontramos que:

${ }^{16}$ El 14-M, El País titula su portada: "Todos los indicios señalan a AlQaeda"; El Mundo: "las primeras detenciones vinculan la masacre con el terrorismo islámico.; 20 Minutos: 11-M: fue AlQaeda.

${ }^{17}$ Para su análisis de las redes sociales y medios alternativos del 11-M al 13-M, Roíg y López (2005) seleccionan dos medios considerados contra-informativos: Nodo50 y La 
- Ya el día 11-M, 26 noticias hablaban de AlQaeda, frente a 6 que atribuían los atentados a ETA.

- El día 12-M van cayendo los indicios que apuntan a ETA: las atribuciones al grupo vasco bajan a una sola, mientras 24 noticias apuntan al terrorismo islámico.

- El día 13-M aumentan a 29 las noticias que apuntan a AlQaeda y sólo dos hablan de ETA.

- En términos totales, el encuadre fijado en estas redes sociales y medios alternativos es fundamentalmente a favor de la hipótesis islamista: se atribuye la autoría a ETA en 9 noticias $(8,7 \%)$ y se apunta a la AlQaeda en $79(76,6 \%)^{18}$.

Es importante señalar que muchas de estas informaciones utilizaron como fuente a medios extranjeros en Internet. "Los medios más concurridos, con la excepción de alguno europeo, son latinoamericanos y norteamericanos (que, a su vez, comparten como fuente las agencias estadounidenses)" (Roíg y López, 2005: 211).

4.5 Conclusiones del estudio: Las redes alternativas en el proceso de enmarcado sobre la autoría del 11-M

Podemos observar cómo el encuadre mantenido insistentemente por el entonces Presidente Aznar y representantes de su Administración contó con casi absoluta supremacía durante las horas siguientes a los atentados. Ello se debió en parte a que la hipótesis de ETA era congruente con los hábitos de pensamiento público debido a la historia precedente y las continuas alusiones a la banda terrorista durante toda la campaña electoral ${ }^{19}$. Los datos recabados por Roíg y López demuestran por el contrario, que entre los medios alternativos triunfó casi desde el primer momento una visión opuesta a la oficial. El encuadre gestado y promovido por los sectores de la sociedad española más jóvenes y próximos a la izquierda (los usuarios habituales de medios contra-informativos y redes socia-

Haine (en los que la publicación está a cargo de un equipo editorial), y dos plataformas de publicación abierta: Indymedia Madrid e Indymedia Barcelona (donde los usuarios tienen la libertad de publicar lo que deseen). Es preciso señalar que en el 2005 todavía no existían las redes sociales de gran difusión que existen hoy día como Facebook o Twitter.

${ }^{18}$ Las 15 noticias restantes $(14,5 \%)$ hacen alusión a diferentes teorías conspiratorias. Por ejemplo se baraja la posibilidad de que fuera obra del propio Gobierno para consolidar su posible victoria electoral, o que en los atentados hubieran participado servicios extranjeros como la CIA.

${ }^{19} \mathrm{El}$ problema del terrorismo de ETA fue tema dominante de la agenda política durante la campaña electoral; de hecho dos terroristas fueron capturados con varios kilos de explosivos en días previos a las elecciones. 
les del grupo Indymedia) fue, con el paso de las horas, extendiéndose rápidamente al resto de la opinión pública y calando en la esfera mediática gracias a las movilizaciones del 12 y 13 de marzo que trasfirieron el marco del espacio virtual al físico. Roíg y López (2005) documentan hasta tres convocatorias promovidas por las redes sociales madrileñas de las que surgieron 4 reuniones, una el mismo 11-M. La mayor repercusión de estas ocupaciones del espacio público la generaron, sin embargo, varios núcleos espontáneos que acudieron a la manifestación oficial del $12-\mathrm{M}^{20}$ en Madrid y que al paso de la cabecera, integrada por representantes institucionales, gritaron "¿Quién ha sido?". Este simple acto supuso un punto de inflexión en la lucha de encuadramientos. Su eficacia se resume en la vasta extensión de la audiencia que fue testigo del mismo. Se calcula que 2,5 millones de personas acudieron a la manifestación convocada por el Gobierno y todos los medios nacionales tenían los ojos puestos en ella. La proyección pública de este nuevo marco, que ya era dominante en los medios alternativos, contribuyó a activar los mecanismos de alerta emocional en el resto de la opinión pública; mecanismos que a su vez mejoraron la capacidad de realizar juicios adecuados. Según la teoría de la inteligencia afectiva ante estímulos emocionales fuertes, las personas tienden a confiar menos en sus predisposiciones y valoran más la información a la hora de hacer juicios. "Mientras que las emociones que tienen que ver con el entusiasmo inducen a hacer valoraciones políticas basadas en la ideología, la ansiedad o el miedo producido por un determinado estímulo activa el sistema de vigilancia y por extensión, el mecanismo de razonamiento para evaluar cuidadosamente la respuesta adecuada a la amenaza percibida" (Castells, 2009: 203). Las implicaciones del nuevo encuadre (el Gobierno miente sobre la autoría de los atentados) contenían una elevada carga emotiva de tipo negativo, lo que contribuyó a aumentar la capacidad de la ciudadanía para analizar la complejidad de las circunstancias y abrió el camino para la aceptación del nuevo contra-frame. Con sectores de la opinión pública oponiéndose a la versión oficial, los medios contaron con una oportunidad real de publicar un punto de vista que desafiaba la línea expresada por el Gobierno. Una oportunidad que vino ayudada por un contexto político propicio y ciertos incentivos profesionales. Las nuevas evidencias policiales señalando la pista islámica y el comunicado de las Brigadas Abu Hafs-Al Masri al periódico Al Quds en Londres contribuyeron a crear el clima de ambigüedad preciso para que los medios pudieran ejercer su autonomía frente a los marcos oficiales. En cuanto a las motivaciones de los periodistas, resultan claros los intereses de los profesionales -sobre todo en

${ }^{20}$ Esta manifestación convocada por el Gobierno ha sido considerada la más multitudinaria de la historia de España. Las cifras hablan de 11,4 millones de manifestantes en todo el país. 
aquellos medios más inclinados a ideologías de izquierdas- para dar cobertura a las interpretaciones disidentes ${ }^{21}$. La presencia cada vez más amplia de contramarcos en la esfera mediática se filtró y retroalimentó a la elite oponente, quien aprovechando el nuevo contexto, lanzó su contra-ofensiva el 13 de marzo. Según señala Entman, las elites tratan de anticipar las posiciones públicas ya existentes sobre una cuestión utilizándolas en la construcción de sus encuadres. Ello es debido a que la aceptación de los nuevos encuadres es más fácil de obtener cuando los mensajes ya reflejan parte del sentir popular. El creciente descontento público sobre la política informativa del Gobierno dio el empuje necesario al resto de líderes y representantes públicos para -en unas circunstancias excepcionalmente delicadas- apoyar decididamente la tesis de AlQaeda y dar rienda suelta al encuadre de la manipulación informativa, que según los resultados del análisis de contenido, adquirió su mayor difusión el día 13 de marzo. Finalmente el triunfo definitivo sobre el encuadre lo adquirieron las voces disidentes el 14 de marzo. Ese día los titulares de los diarios de mayor difusión atribuían sin paliativos el atentado al terrorismo yihaidista. Todo parece indicar que este vuelco definitivo fue también fruto de las movilizaciones organizadas a través de los medios alternativos y especialmente el sistema de mensajería móvil SMS en la noche previa a las elecciones. "Estos textos, cortos pero directos, sin firma ni atribución partidista consiguieron convocar entre 4.000 y 5.000 personas en la calle Génova de Madrid; y multiplicar las concentraciones y decenas de caceroladas en diversos barrios de la capital" (Alcalde, Sábada y Sampedro, 2005: 175). El encuadre logró triunfar a tiempo para transformar la realidad social y contribuir a que el partido en el poder -que antes de los atentados se encontraba a 5 puntos por delante en las encuestas- perdiera las elecciones quedando a 10,3 puntos por detrás del partido vencedor. Este resultado tuvo además un impacto directo en la política exterior española, siendo el detonante político para la inmediata retirada de las tropas españolas en territorio iraquí.

\section{CONCLUSIONES GENERALES}

Las redes alternativas de comunicación, creadas alrededor de las comunicaciones móviles e Internet, han irrumpido en la esfera social como una fuente de contra-poder al servir a los ciudadanos de espacio libre y abierto para conectar y comunicarse. Su penetración en todos los ámbitos de la sociedad ha revolucionado la capacidad de la ciudadanía para cohesionar un movimiento social que acabe derivando en un proceso de construcción social de significados dis-

${ }^{21}$ Parece claro que el contra-frame contribuiría a generar más audiencia sobre todo entre los lectores de izquierdas. La vocación profesional y los deseos de reconocimiento también pueden encontrarse entre las motivaciones de los periodistas. 
tintos. En el ámbito de la comunicación política las redes sociales y móviles ocupan ya un espacio privilegiado al desempeñar la función decisiva de fijar el marco de discusión pública. En este sentido, su función es la de impactar en la construcción del poder político activando nuevos marcos de referencia que desencadenan la acción de otras redes de poder y contribuyen a definir nuevas realidades. En los modelos constructivistas del encuadre observamos que estas redes virtuales de interacción social constituyen un elemento clave para que la opinión pública logre cohesionar sus marcos individuales de manera que adquieran fuerza y peso suficientes para triunfar en la esfera mediática y derrotar los marcos de la clase dominante. En este sentido, la facilidad con que la elite política -dado su acceso privilegiado a los medios- solía imponer sus definiciones de la realidad en la esfera mediática, queda contrarestada por la nueva capacidad del público para, en ocasiones desafiar dichas interpretaciones, y en otras, ganar la atención de los medios en torno a sus demandas, mensajes e interpretaciones propias de una forma mucho más eficaz. Ello se consigue difundiendo, conectando y consensuando las definiciones individuales con otras personas que interactúan en la Red hasta conseguir aunar una respuesta común en el espacio público. Aunque en asuntos relacionados con la política internacional la elite política se sigue colocando a la cabeza del proceso de enmarcado, las redes alternativas están constituyéndose, de hecho, como una herramienta fundamental en manos de las masas para fijar nuevos temas en la agenda de los medios y tomar la iniciativa del encuadramiento en asuntos nacionales.

\section{BIBLIOGRAFÍA}

ALTHUSSER, L. (1969). "Ideology and Ideological State Apparatuses (Notes towards an Investigation) en ALTHUSSER, L. (1971). Lennin and philosophy and other Essays. New York and London: Monthly, Review Press, 127.

ATTON, C. (2002). Alternative Media. London: Sage. (2004). An Alternative Internet. Edinburgh: Edinburgh University Press.

CARRAGEE, K.; ROEFS W. (2004). "The Neglect of Power in Recent Framing Research", International Communication Association. 214-233.

COULDRY, N. and CURRAN, J. (2003). "The Paradox of Media Power" en Couldry, N. and Curran, J. (eds) Contesting Media Power: Alternative Media in a Networked World. Lanham, MD: Rowman \& Littlefield, 3-15.

CASTELLS, M. (2009). Comunicación y poder. Madrid: Alianza editorial.

DAMASIO, A. (2003). Looking for Spinoza: Joy, Sorrow, and the Feeling Brain. Orlando: Harcourt.

ENTMAN, R. (2004). Projections of power, framing news, public opinion and U.S. Foreing Polic., Chicago: University of Chicago Press.

FOUCAULT, M (1970). La arqueología del saber. Madrid: Siglo XXI. 
FUCHS, C. (2010). "Alternative media as critical media". European Journal of Social Theory Núm. 13, Vol. 2, 173-192. (2011) Foundations of Critical Media and Information Studies. New York: Routledge.

GAMSON, W.A. (1992). "The Social Psychology of Collective Action" Frontiers in Social Movement Theory, A.D. Morris and C.M. Mueller. New Haven, CT: Yale University Press, 53-76

GRAMSCI, A. (1975). Cartas desde la cárcel. Madrid: Cuadernos para el diálogo.

GIDDENS, A. (1984). The Constitution of Society. Cambridge: Polity Press.

HABERMAS, J. (1989). The Structural Transformation of the Public Sphere. Cambridge, MA: MIT Press.

HALLIN, D. (1989). The Uncensored War: The Media and Vietnam. Berkeley: University of California Press.

(1992). "Soundbite news, television coverage of elections, 1968-1988" Journal of communication, Vol 42, Núm 2, 5-24.

HALLIN, D.; Mancini, P. (2004). Comparing media systems, three models of media and politics. Cambridge: Cambridge University Press.

KAPPLER, J. (1960). The effects of mass communication. New York: Free press.

LAKOFF, G. (2008). The Political Mind: Why You Can't Understand 21st-Century American Politics with an 18th-Century Brain. New York: Viking.

LIVINGSTON, S.; BENNETT W.L (2003). "Gatekeeping, Indexing, and Live-Event News: Is Technology Altering the Construction of News?" Political Communication, Vol 20, 363-380.

MARCUSE, H. (1969). One-Dimensional Man: studies in the ideology of advanced industrial society. Beacon Press, Boston.

MCCOMBS M.; SHAW D. (1972). "The agenda-setting function of mass media", Public Opinion Quarterly, Núm. 36, 176-187

MOROZOV, E. (2011). The dark side of Internet Freedom. New York: Public Affairs.

ROBINSON, P. (2011). "The CNN Effect Reconsidered: mapping a research agenda for the future." Media, War and Conflict, Vol 4, Núm. 1, 3-11.

ROÍG, G.; LÓPEZ S. (2005). "Del desconcierto emocional a la movilización política: redes sociales y medios alternativos del 11-M al 13-M" en Sampedro, V. 13-M Multitudes online. Madrid: Catarata, 183-228.

SAMPEDRO, V.; ALCALDE J.; SÁBADA I. (2005). "El fin de la mentira prudente. Colapso y apertura de la esfera pública" en SAMPEDRO, V. 13-M Multitudes online. Madrid: Catarata, 229-278.

SCHUDSON, M. (2003). The sociology of news. New York: W.W. Norton \& Company.

SCHEUFELE, D. (1999). "Framing as a Theory of Media Effects", Journal of Communication, Vol 49, Núm. 1, 103-122.

TOURAINE, A. (1995). Producción de la sociedad. México: UNAM-IFAL.

THORN, H. (2007). "Social Movements, the Media and the Emergence of a Global Public Sphere", Current Sociology, Núm. 55, Vol. 6, 896-918. 